\title{
INTERNALIST FOUNDATIONALISM AND THE PROBLEM OF THE EPISTEMIC REGRESS*
}

José L. Zalabardo

University College London

\begin{abstract}
I provide a construal of the epistemic regress problem and I take issue with the contention that a foundationalist solution is incompatible with an internalist account of warrant. I sketch a foundationalist solution to the regress problem that respects a plausible version of internalism. I end with the suggestion that the strategy that I have presented is not available only to the traditional versions of foundationalism that ascribe foundational status to experiential beliefs. It can also be used to generate a version of internalist foundationalism based on reliabilist principles.
\end{abstract}

\section{Logical Preliminaries}

Let a sprouting function on a set $A$ be a function pairing each element of $A$ with a subset of $A$. Let $f$ be a sprouting function on a set $A$, and let $a$ be an element of $A$. Let's refer to the elements of $f(a)$, if it has any, as the offshoots of $a$. By the $f$-tree of $a$, we shall refer to the set containing the offshoots of $a$, if there are any, the offshoots of these, if there are any... and nothing else. And by an $f$-branch of $a$, we shall refer to any of the subsets of $A$ that you generate by picking exactly one offshoot of $a$, if it has any, exactly one offshoot of this, if it has any... (See the appendix for formal definitions.)

We can now define three properties that a sprouting function $f$ on a set $A$ might exhibit. First, let's say that $f$ is total if every element of $A$ has offshoots (i.e. no element of $A$ has the empty set as its image under $f$ ). Second, let's say that $f$ is non-circular if no element of $A$ is an element of its own $f$-tree. Third, let's say that $f$ is finitary if every $f$-branch is finite. ${ }^{1}$

We end these logical preliminaries by formulating the following straightforward result about sprouting functions (see the appendix for a proof):

\footnotetext{
* I am grateful to an anonymous referee for this journal.

${ }^{1}$ Notice that an $f$-tree can contain infinitely many elements of $A$ and still be finitary, if (and, by König's Lemma, only if) any of its elements has infinitely many offshoots.
} 
Agrippa's Theorem: If $A$ is a nonempty set, there are no total, non-circular, finitary sprouting functions on $A$.

By virtue of Agrippa's Theorem, whenever we can establish that there has to be a total, noncircular, finitary sprouting function on a set $A$, we will be able to conclude that $A$ is the empty set.

\section{The Epistemic Regress Argument}

Agrippa's Theorem is the basic logical fact at the heart of the epistemic regress argument. My goal in this section is to provide a construal of the argument in which the role of the theorem is made perspicuous. My construal will rest on three assumptions about knowledge.

The first assumption that I want to make is the standard tripartite account of knowledge, according to which believing truly that $p$ is necessary but not sufficient for knowing that $p$, and there is a nontrivial condition whose satisfaction or otherwise will determine whether a given case of true belief is a case of knowledge. I shall construe this condition as a relation between a subject and a proposition (at a time), and refer to it as warrant. ${ }^{2}$ Thus if $S$ believes that $p$ (at $t$ ) and $p$ is true, $S$ will know that $p$ (at $t$ ) just in case $p$ has warrant for $S($ at $t){ }^{3}$

The second assumption that I want to make is that the warrant condition in the tripartite account of knowledge is independent of the belief condition: It is possible in principle for a subject to have warrant for a proposition that she doesn't believe. I shall refer to this assumption as the belief independence of warrant. To provide a precise formulation of the

\footnotetext{
${ }^{2}$ I am making no assumptions about the nature of this condition. In particular, I am not assuming that it has anything to do with justification or reasons. This is the use of the term warrant associated with Alvin Plantinga. See Alvin Plantinga, Warrant: The Current Debate (New York and Oxford: Oxford University Press, 1993).

${ }^{3}$ When a subject and a proposition are connected by the warrant relation (at a time), I shall say indistinctly either that the proposition has warrant for the subject or that the subject has warrant for the proposition, ascribing grammatical possession of warrant to the proposition or the subject according to stylistic convenience.
} 
belief-independence assumption, we need to look in some detail at the structure of warrant. ${ }^{4}$ We can think of the warrant condition as a collection of relations $W_{1}, \ldots, W_{n}$ between subjects and propositions, such that, if a subject $S$ believes a true proposition $p, S$ will know that $p$ if and only if $S$ bears to $p$ at least one of $W_{1}, \ldots, W_{n}{ }^{5}$ Let me refer to each of $W_{1}, \ldots, W_{n}$ in this schema as a warrant source.

Now, each warrant source can be expected to consist of positive conditions and negative conditions, or defeaters. Thus a warrant source will be satisfied just in case its positive conditions are satisfied and its defeaters are not satisfied. ${ }^{6}$ Finally, let's say that a condition (positive or negative) of a warrant source is belief independent just in case a subject can satisfy it with respect to a proposition without believing it.

We can now provide a precise formulation of the belief-independence assumption. It is the assumption that there is at least one warrant source whose positive conditions are belief independent. Notice that, thus formulated, the assumption has two important features. First, it is compatible with the existence of warrant sources whose positive conditions are belief dependent. Second, it is compatible with the possibility that all warrant sources have beliefdependent defeaters.

If $S$ doesn't believe that $p, p$ can still have warrant for $S$ if $S$ satisfies with respect to $p$ a warrant source with belief-independent positive conditions. If $p$ is true, then only the failure of the belief condition will stop $S$ knowing that $p$. Nevertheless, it doesn't follow that if $S$

\footnotetext{
${ }^{4}$ What follows is meant to supersede the more casual presentation of the belief independence of warrant that I provided in José Zalabardo, "Externalism, Skepticism and the Problem of Easy Knowledge," Philosophical Review 114 (2005). I am grateful to Mike Martin, who first alerted me to the problems attending the more simplistic approach that I adopted there.

${ }^{5}$ That is, with the obvious abbreviations, the definition of knowledge will have the following form:

$K n(S p t) \equiv \operatorname{Bel}(\operatorname{Spt}) \& v(p)=T \&\left(W_{1} \vee \ldots \vee W_{n}\right)$

${ }^{6}$ If we denote the positive conditions of $W_{i}$ by $W_{i}^{+}$, and its negative conditions by $W_{i}^{-}$, the definition of knowledge will have the following form:

$K n(\operatorname{Spt}) \equiv \operatorname{Bel}(\operatorname{Spt}) \& v(p)=T \&\left(\left({W_{1}}^{+} \& \sim W_{1}^{-}\right) \vee \ldots \vee\left(\left({W_{n}}^{+} \& \sim W_{n}^{-}\right)\right)\right.$.
} 
formed the belief that $p$ she would ipso facto come to know that $p$. Knowledge would only ensue if, in the process of forming the belief, $S$ doesn't cease to satisfy the warrant source with respect to $p$. This possibility will be particularly salient if the warrant source in question has belief-dependent defeaters. ${ }^{7}$

The third assumption that I want to make is that for any cognitive subject $S$, proposition $p$ and time $t$, there will be a fact of the matter as to whether $p$ has warrant for $S$ at $t$. By reference to these facts, we can define, for every subject $S$ and time $t$, the set containing those propositions which have warrant for $S$ at $t$. I shall refer to this assumption as epistemological realism. I shall refer to the set of propositions that have warrant for $S$ at $t$ as $S$ 's warrant set at t. Since $S$ might believe propositions which have no warrant for her, and there might be in principle propositions that have warrant for her but she doesn't believe, $S$ 's warrant set at $t$ will probably neither include, nor be included in, the set of propositions that $S$ believes at $t$.

With these assumptions in place, we can formulate an argumentative strategy for establishing the sceptical result that knowledge is impossible. Suppose that we could show that, for every warrant set $W$, there has to be a total, non-circular, finitary sprouting function on $W$. Then we could conclude, by Agrippa's Theorem, that every warrant set has to be empty, and, a fortiori, that knowledge is impossible. I want to suggest that this argumentative strategy constitutes the core of the epistemic regress argument against the possibility of knowledge. This claim can't be made very precise, since it might not be entirely clear what pieces of reasoning should be counted as versions of the regress argument. Nevertheless, the hypothesis that I am putting forward is that if it can be shown that there has to be a total, noncircular, finitary sprouting function on every warrant set, then we should conclude that the

\footnotetext{
${ }^{7}$ Suppose that $S$ satisfies with respect to $p$ the positive conditions of a warrant source, which are belief independent, but fails to satisfy the warrant source because she satisfies, with respect to $p$, its (belief-dependent) defeaters. Then it might be natural to say that $p$ has warrant for $S$, but $S$ 's belief that $p$ lacks warrant. Cf., in this connection, James Pryor, "Highlights of Recent Epistemology," British Journal for the Philosophy of Science 52 (2001): pp. 104-05.
} 
epistemic regress argument succeeds in establishing that knowledge is impossible, but if this can't be done, then no piece of reasoning that we would recognise as a version of the regress argument will succeed in establishing the impossibility of knowledge. ${ }^{8}$

These considerations set a very clear agenda for the regress sceptic. She needs to identify a sprouting function on a warrant set of which she can claim that it has to be total, non-circular and finitary. Where will the sceptic find such a function? Presentations of the regress argument typically start by considering the phenomenon of inferential warrant. In cases of inferential warrant, a proposition $p$ has warrant for a subject as a result of a relation that it bears to other propositions that have warrant for the subject, where the latter propositions provide the subject with reasons, or evidence, for thinking that $p$ is (probably) true. Thus, for example, the proposition that the butler committed the murder might come to have warrant for the detective as a result of its connection with a set of propositions for which the detective has warrant, including, prominently, the proposition that the butler's fingerprints match those found around the victim's throat.

There are different views on how a proposition (the conclusion) has to be related to a set of propositions (the premises) in order to generate a case of inferential warrant. On some views, the premises have to probabilify the conclusion. On other views, the subject has to have warrant for the proposition that the premises probabilify the conclusion. ${ }^{9}$ I shall not enter in

\footnotetext{
${ }^{8}$ In restricting my discussion to the role of the regress argument in establishing the conclusion that knowledge is impossible, I am leaving out of the picture the ways in which the ancient sceptics sought to use the argument. The major exponents of ancient scepticism, both Pyrrhonian and Academic, explicitly refrained from endorsing the view that knowledge is impossible, and criticised those who held this view as no less dogmatic than those who held that knowledge was possible, accusing them of being pseudo-sceptics. Cf. Michael Frede, "The Skeptic's Two Kinds of Assent and the Question of the Possibility of Knowledge," in Philosophy in History. Essays on the Historiography of Philosophy, ed. Quentin Skinner (Cambridge: Cambridge University Press, 1984), pp. 255, 268-71. Even if the regress argument failed to establish the impossibility of knowledge, it might successfully discharge the roles that the ancient sceptics assigned to it.

${ }^{9}$ See Alston's discussion of these possibilities in William P. Alston, "Internalism and Externalism in Epistemology," Philosophical Topics 14 (1986): pp. 188-89. Other views are also possible. A demand that is often associated with Cartesian epistemology is that inferential warrant requires that the premises logically entail the conclusion.
} 
this debate, since the prospects for the regress argument, as I am going to construe it, do not depend on which option one takes at this point.

A much less controversial requirement is that in order for a proposition to obtain warrant inferentially for a subject from its relation to other propositions, the latter will also have to have warrant for the subject. One intuition supporting this requirement is that when a proposition $p$ obtains warrant inferentially, it inherits it from other propositions to which it is suitably related. And $p$ cannot inherit from other propositions warrant that the latter don't possess.

Now, if we assume, for the sake of simplicity, that no proposition obtains inferential warrant independently from two different sets of propositions, we can define a sprouting function on a subject's warrant set as the function pairing each inferentially warranted proposition with the set of propositions from which it inherits its warrant, and every other warranted proposition with the empty set. Let me refer to this function as the inferentialwarrant function. If it could be shown that the inferential-warrant function has to be total, non-circular and finitary, Agrippa's Theorem would yield the conclusion that knowledge is impossible, and we would have to concede defeat to the regress sceptic.

\section{Foundationalism}

Pursuing this sceptical strategy would require showing that the inferential-warrant function has to be total, non-circular and finitary. None of these requirements has gone uncontested, but for at least two of them intuition seems to favour the sceptic. It is accepted that a proposition can obtain warrant inferentially form other propositions that inherit their own warrant inferentially from other propositions, etc. But it seems natural to suppose that the resulting inferential tree will bestow warrant on the target proposition only if every one of its branches is finite and if the target proposition doesn't figure in it. And it would follow from 
this that the inferential-warrant function has to be non-circular and finitary. As I say, neither of these requirements is universally accepted, and I shall not try to argue that they are legitimate. ${ }^{10}$ My goal is to consider the prospects for the regress argument if these requirements are accepted. Hence I propose to assume for the sake of the argument that the inferential warrant function is non-circular and finitary, and consider how the regress sceptic would have to proceed to close the remaining gap in her reasoning.

Obviously, the most direct strategy for completing the reasoning would be to argue that the inferential warrant function has to be total, i.e. that inferential warrant is the only kind of warrant there is. However, I think it is fair to say that here intuition isn't as firmly on the side of the sceptic as with the other two requirements. In the absence of philosophical argument to the contrary, there doesn't seem to be anything obviously wrong with the idea of a proposition that has warrant for a subject which doesn't arise from its inferential relation to other propositions that have warrant for the subject. Furthermore, an argument against noninferential warrant would have to be highly cogent to find acceptance among those who consider non-circularity and finitariness irresistible. For the consequences of Agrippa's Theorem in this area have long been recognised: it is universally accepted that in the presence of these two constraints, rejecting non-inferential warrant would force us to reject the possibility of knowledge. In fact, perhaps the most common use of Agrippa's Theorem is not in an argument against the possibility of knowledge, but in an argument using non-circularity, finitariness and the possibility of knowledge as premises to derive the conclusion that some warrant has to be non-inferential. ${ }^{11}$

\footnotetext{
${ }^{10}$ Non-circularity is rejected by coherentists (see $\$ 4$, below). For a position that rejects finitariness, see Peter Klein, "Human Knowledge and the Infinite Regress of Reasons," in Philosophical Perspectives, 13, Epistemology, ed. James E. Tomberlin (Cambridge, Massachusetts: Blackwell, 1999).

${ }^{11}$ See Aristotle, Posterior Analytics, trans. Jonathan Barnes, 2nd ed. (Oxford: Clarendon Press, 1994), A 3.
} 
These considerations confer something of a default status on the traditional foundationalist account of warrant. I propose to construe foundationalism as the position that accepts the finitariness and non-circularity conditions on inferential warrant, holding that these can be satisfied by substantial warrant sets, thanks to the ready availability of non-inferentially warranted propositions. These provide the end-points of finite branches of non-circular trees from which other propositions obtain their warrant. So long as this foundationalist picture is available, regress scepticism won't pose a threat.

\section{The Internalist Argument}

Now, even if we could show that non-inferential warrant is a possibility, the foundationalist picture would still face a number of important challenges. But if non-inferential warrant turned out to be impossible, foundationalism would be a non-starter, and unless noncircularity or finitariness could be repealed, regress scepticism would prevail. One line of reasoning against the possibility of non-inferential warrant that has received a good deal of attention in recent debates seeks to establish its conclusion from a premise to the effect that warrant should be construed along internalist lines. I shall refer to this line of reasoning as the internalist argument against non-inferential warrant.

The label internalism is used in epistemology to denote a broad collection of loosely related theses, and the cogency of the internalist argument against non-inferential warrant is likely to depend on which version of internalism it invokes as a premise. One of the main strands of the internalist position is the thought that the subject has to enjoy a special kind of cognitive access to the facts as a result of which a proposition comes to have warrant for her. Naturally, this thought would only impose a substantial constraint on an account of warrant in the presence of a background assumption to the effect that, whenever a proposition has warrant for a subject, this is so as a result of some other fact. Nevertheless, a view along these 
lines enjoys widespread support. For the specific case of non-inferential warrant that interests us, it can be formulated as follows:

Non-Primitivism: If a proposition $p$ has non-inferential warrant for a subject $S$ (at time $t$ ), then there is a non-epistemic fact $F$ that constitutes the fact that $p$ has warrant for $S$ (at $t$ ).

Notice that on this formulation the principle is neutral as to the nature of the constitution relation, although it is generally construed as a form of supervenience. ${ }^{12}$

We can now understand the form of internalism on which I want to focus as imposing a restriction on which non-epistemic facts can play the constituting role in cases of noninferential warrant. According to internalism, this role can be played only by facts to which the subject enjoys a special kind of access.

We still don't have a fully specific construal of internalism, as different versions of the thought will result depending on which kind of cognitive access to the warrant-constituting facts is demanded. Familiar forms of internalism dictate that the subject has to have infallible access to these facts, or that they have to be knowable to the subject by reflection alone. ${ }^{13}$ Here I want to focus on a relatively undemanding version of the thought, according to which the subject has to be related to the warrant-constituting fact in the following way: she has to have warrant for the proposition that the fact obtains. Now we can formulate the version of internalism on which I want to focus. I shall use for it the label Minimal Internalism, since, even though it might not be strictly entailed by every version of internalism, it is hard to see how its rejection could be made compatible with the spirit of the internalist approach:

\footnotetext{
${ }^{12}$ See James Van Cleve, "Epistemic Supervenience and the Circle of Belief," The Monist 68 (1985).

${ }^{13}$ Alston refers to this form of internalism as Access Internalism. See Alston, "Internalism and Externalism in Epistemology," pp. 203-05. Notice, however, that Pryor uses the label for a different position. The view that he calls Direct Internalism is a version of the form of internalism I have in mind. Cf. Pryor, "Highlights of Recent Epistemology," pp. 103-05.
} 
Minimal Internalism: A non-epistemic fact $F$ can constitute the fact that a proposition $p$ has warrant for a subject $S$ (at time $t$ ) only if the proposition that $F$ obtains has warrant for $S($ at $t)$.

We can now use this construal of internalism to examine in some detail a version of the internalist argument against non-inferential warrant. The reasoning can be presented as a reductio. Let the proposition that $p$ have warrant for subject $S$ (at time $t$ ). We assume, towards a contradiction, that $p$ 's warrant for $S$ is non-inferential. Then, by Non-Primitivism, there has to be a non-epistemic fact $F$ that constitutes the fact that $p$ has warrant for $S$. But then, by Minimal Internalism, the proposition that $F$ obtains has to have warrant for $S$. Therefore $p$ won't have warrant for $S$ unless another proposition - the proposition that $F$ obtains - has warrant for her, and this contradicts the hypothesis that $p$ 's warrant is non-inferential. On the contrary, it is inferentially inherited from the proposition that $F$ obtains.

Notice that, for every branch of an inferential-warrant tree that a foundationalist claims to have brought to an end after a finite number of steps, this reasoning gives us a precise account of how the branch ought to continue. If the foundationalist claims to have brought a branch to an end with the proposition that $p$, then if $F$ is the non-epistemic fact that constitutes the fact that $p$ has warrant for the subject, the branch ought to continue with the proposition that $F$ obtains. And obviously, by the same reasoning, this proposition can't provide an end-point for the branch either. If the foundationalist claims that the proposition that $F$ obtains has noninferential warrant for the subject, the branch will have to continue with the proposition representing the warrant-constituting fact for this proposition (i.e. for the proposition that $F$ obtains). The result will have to be an infinite branch unless the non-circularity constraint is violated. 


\section{Two Reactions}

There are two prominent positions in contemporary epistemology that sustain different strategies for accommodating the internalist argument without conceding defeat to the regress sceptic. The first is the coherentist account of warrant. Coherentists typically accept the conclusion of the internalist argument: inferential warrant is the only kind of warrant there is. ${ }^{14}$ Nevertheless, coherentists don't take this result to render warrant impossible, since on the coherentist picture a proposition can in principle have warrant for a subject even if its inferential-warrant tree violates the non-circularity constraint. Thus, even if she accepts that the inferential warrant function is total and finitary, for the coherentist the possibility of warrant is not threatened by the application of Agrippa's Theorem to the inferential warrant function. So long as it is allowed to be circular, a total, finitary sprouting function on a nonempty set is in principle unproblematic.

The second position that I want to consider is the externalist account of warrant. Externalists typically accept that non-inferential warrant has to be constituted by nonepistemic facts, but they openly reject restrictions on which facts can play the constituting role based on the kind of cognitive access that the subject enjoys to them. Hence they can be expected to regard as perfectly possible that a non-epistemic fact $F$ has warrant-constituting powers even if the proposition that $F$ obtains doesn't have warrant for the subject. In this way, by rejecting the central premise of the internalist argument, the externalist immediately defuses the threat that it poses to non-inferential warrant. This enables her to rescue the

\footnotetext{
${ }^{14}$ Of course, a coherentist can reject internalism and/or the internalist argument against non-inferential warrant, even though the rejection of non-inferential warrant is intrinsic to her position.
} 
foundationalist picture, upholding the possibility of warrant while conceding that the inferential warrant function is non-circular and finitary. ${ }^{15}$

Notice that coherentists and externalists alike can try to enlist the internalist argument in support of their view. On the one hand the appeal of the coherentist solution to the regress problem will be undoubtedly enhanced if we are persuaded by the internalist argument that non-inferential warrant is not a possibility. ${ }^{16}$ On the other hand, for those who regard the finitariness and non-circularity of inferential warrant as non-negotiable, the internalist argument presents an externalist version of foundationalism as the only credible answer to regress scepticism. ${ }^{17}$ Proponents of this line of thought would use the internalist argument, not in support of its conclusion, but as a reductio of its main premise.

\section{BonJour's Proposal}

Other antisceptical alternatives might be left open by the internalist argument. In any case, one particular strategy for saving the possibility of warrant from the consequences of Agrippa's Theorem would appear to emerge as a clear casualty of the internalist argumentnamely an internalist version of the foundationalist picture. For the foundationalist account of how warrant is possible presupposes a plentiful supply of non-inferentially warranted propositions, while the internalist argument appears to show that, for the internalist, noninferential warrant is not to be had.

\footnotetext{
${ }^{15}$ The idea of solving the epistemic regress problem with an externalist version of foundationalism was pioneered by David Armstrong. See David M. Armstrong, Belief, Truth and Knowledge (London: Cambridge University Press, 1973), Chapter 11.

${ }^{16}$ This is clearly the route that led BonJour to embrace coherentism. See Laurence BonJour, The Structure of Empirical Knowledge (Cambridge, Massachusetts: Harvard University Press, 1985).

${ }^{17}$ For Armstrong, externalist foundationalism receives support from this line of reasoning. See Armstrong, Belief, Truth and Knowledge, Chapter 11. Other externalists have sought to present their position as the only alternative to scepticism. See John Greco, Putting Skeptics in Their Place (Cambridge: Cambridge University Press, 2000), Michael Bergmann, "Externalism and Skepticism," Philosophical Review 109 (2000).
} 
The most forceful presentation of this challenge to internalist foundationalism is to be found in the work of Laurence BonJour. ${ }^{18}$ In the 1970s and 1980s, BonJour saw the coherence theory as the only viable account of warrant. ${ }^{19} \mathrm{He}$ was lead to this conclusion by his commitment to internalism and his conviction that this position leads, through a version of the internalist argument, to the impossibility of non-inferential warrant.

Nevertheless, in recent years BonJour has abandoned coherentism and embraced a version of internalist foundationalism. ${ }^{20} \mathrm{I}$ am going to consider in this section to what extent BonJour's current position can overcome the challenge of the internalist argument, but I want to emphasize that the consistency of BonJour's position is not at issue here. I think it is unquestionable that BonJour was committed to Minimal Internalism in his coherentist days. He maintained that if $B$ is a non-inferentially warranted belief of subject $S$, and $\phi$ is the feature of $B$ by virtue of which it qualifies as non-inferentially warranted for $S$, then the proposition that $B$ has feature $\phi$ will have to have warrant for $S$, as Minimal Internalism requires. ${ }^{21}$ However, it is far from clear that in his current foundationalist period he still subscribes to the principle. ${ }^{22}$ In any case, my own concern is to determine whether a foundationalist solution to the regress argument can be made compatible with Minimal Internalism, and I want to consider whether BonJour's version of foundationalism can serve this purposeindependently of whether BonJour thinks it does.

\footnotetext{
${ }^{18}$ See Laurence BonJour, "Can Empirical Knowledge Have a Foundation?," American Philosophical Quarterly 15 (1978), BonJour, The Structure of Empirical Knowledge, Chapter 2.

${ }^{19}$ Notice, though, that BonJour only endorsed this conclusion for empirical knowledge.

${ }^{20}$ See Laurence BonJour, "The Dialectic of Foundationalism and Coherentism," in The Blackwell Guide to Epistemology, ed. John Greco and Ernest Sosa (Malden, Massachusetts and Oxford: Blackwell, 1999) and his contribution to Laurence BonJour and Ernest Sosa, Epistemic Justification. Internalism Vs. Externalism, Foundations Vs. Virtues (Malden, Massachusetts: Blackwell, 2003), entitled "A Version of Internalist Foundationalism".

${ }^{21}$ See BonJour, "Can Empirical Knowledge Have a Foundation?," p. 6, BonJour, The Structure of Empirical Knowledge, p. 31.

${ }^{22}$ I am grateful to an anonymous referee for this journal for alerting me to this fact.
} 
BonJour's preferred formulation of his commitment to an internalist account of warrant in recent writings is not along the lines of Minimal Internalism, but a principle linking warrant with reasons:

The Reasons-Warrant Principle (RW): A proposition $p$ has warrant for a subject $S$ only if $S$ is in cognitive possession of a reason why $p$ is likely to be true. ${ }^{23}$

RW poses an obvious challenge to non-inferential warrant. We have a clear model of how a subject can be in cognitive possession of a reason why $p$ is likely to be true - namely by having inferential warrant for $p$. But this model is obviously not available for noninferentially warranted propositions. To resolve the tension, a different model of cognitive possession of reasons would have to be found. BonJour thinks that a suitable alternative is available for propositions that describe the content of the subject's conscious sensory experience (experiential propositions, for short). BonJour's basic thought is that a state of sensory experience

[...] essentially involves a constitutive, or "built in", non-apperceptive awareness of its own distinctive sort of content. And [...] such a constitutive awareness of sensory content is in no need of justification $[\ldots]{ }^{24}$

BonJour's alternative model of cognitive possession of reasons arises from this phenomenon:

Such a built in awareness of sensory content is thus also apparently available to justify genuinely foundational beliefs [...]. Thus if I have the belief that, e.g., my present visual experience includes a red, square patch in the approximate middle of my visual field, and if my constitutive or built-in awareness of the content of my actual conscious visual experience includes an awareness of such an element, then this latter awareness seems to provide a clear and compelling reason for thinking that the belief is true. ${ }^{25}$

\footnotetext{
${ }^{23}$ See, e.g., BonJour, "The Dialectic of Foundationalism and Coherentism," p. 118. He already subscribed to this principle in his coherentist period. See BonJour, The Structure of Empirical Knowledge, p. 8.

24 “A Version of Internalist Foundationalism”, p. 70.

${ }^{25}$ Ibid.
} 
If this is a satisfactory picture, then being in cognitive possession of a reason why an experiential proposition is likely to be true will not require having inferential warrant for the proposition. Therefore RW will no longer pose an obstacle to the possibility of non-inferential warrant. This is, in broad outline, how BonJour seeks to resolve the tension between noninferential warrant and internalism, construed along the lines of RW.

I shall not try to assess here BonJour's strategy for making non-inferential warrant compatible with RW. My goal is to consider whether the resources that BonJour deploys for this purpose can be used to make inferential warrant compatible with Minimal Internalism. I am going to argue that they can't be successfully used in this way.

Let $p$ be an experiential proposition concerning $S$ 's conscious sensory experience. Assume, for the sake of the argument, that, by virtue of the built-in awareness involved in the relevant sensory episode, $S$ is in cognitive possession of a non-inferential reason why $p$ is likely to be true. Now, it follows from this assumption that in order to satisfy the necessary condition on warrant laid down by RW, S's warrant for $p$ doesn't have to be inferential.

Nevertheless, I want to argue that, even if we concede this, the situation with regard to my construal of the internalist argument remains unchanged. If $p$ is to have warrant for $S$, there will have to be a non-epistemic fact $F$ that constitutes the fact that $p$ has warrant for $S$, and then, by Minimal Internalism, $S$ will have to have warrant for the proposition that $F$ obtains. This means, by the reasoning presented in $\S 3$, that $S$ 's warrant for $p$ will have be inferential after all. Even if we concede to BonJour that $S$ is in cognitive possession of a non-inferential reason why $p$ is likely to be true, the fact remains that the internalist argument shows that $S$ won't have warrant for $p$ unless she has warrant for the proposition that $F$ obtains, and hence that her warrant for $p$ is inferential all the same.

I conclude that BonJour's non-inferential model of reasons doesn't provide a strategy for making non-inferential warrant compatible with Minimal Internalism. I think, however, that 
internalist foundationalism can overcome the difficulties that we have been discussing. My goal in the remainder is to present a strategy for attaining this goal. I am going to sketch an account of how Minimal Internalism can be made compatible with non-inferential warrant, thus removing the obstacle to internalist foundationalism posed by the internalist argument.

\section{A Gap in the Argument}

I'm going to start by pointing out a gap in the reasoning of the internalist argument. Recall that the argument assumes, towards a contradiction, that $S$ has non-inferential warrant for $p$ (see §3). From this assumption, Non-Primitivism and Minimal Internalism, we need to derive:

\section{(A) $S$ 's warrant for $p$ is inferential.}

We derive this conclusion from the claim:

(B) $S$ 's warrant for the proposition that $F$ obtains is a necessary condition for $S$ 's warrant for $p$.

(B) follows directly from our assumptions, but the transition from (B) to (A) is less straightforward. It would be licensed by the principle:

(C) Whenever S's warrant for a proposition $\phi$ has as a necessary condition that $S$ has warrant for other propositions, S's warrant for $\phi$ is inferential.

With this principle in place, the necessary condition on $S$ 's warrant for $p$ imposed by Minimal Internalism would render this warrant inferential. But the principle is problematic. When S's warrant for $p$ is inferential, it will have as a necessary condition S's warrant for some other proposition. But for $(\mathrm{C})$ to hold, every case in which such a necessary condition is in force would have to count as a case of inferential warrant. And there is no obvious reason why we 
should accept this. Inferential warrant has other features that may or may not be present in any given instance in which the warrant of a proposition has as a necessary condition the warrant of other propositions. In particular, on the construal that results from acceptance of Minimal Internalism, non-inferential warrant remains different from inferential warrant in important respects.

Notice first of all that on the Minimal Internalist construal of non-inferential warrant, in order for $p$ to have non-inferential warrant for $S$ it's not enough that the proposition that $F$ obtains has warrant for $S$. In addition to this, $F$ has to obtain. There is no parallel requirement for inferential warrant. If a proposition inherits its warrant inferentially from other propositions, the latter propositions will have to have warrant, but there is no additional requirement that they have to be true - that the facts that they represent have to obtain. ${ }^{26}$

Furthermore, Minimal Internalism does not entail that (the singleton of) the proposition that $F$ obtains should be related to $p$ in whatever way is required by any specific account of the inferential-warrant function. Thus, e.g., we might subscribe to an account of inferential warrant according to which the premises have to probabilify the conclusion, while not requiring that a non-inferentially warranted proposition has to be probabilified by the proposition representing the corresponding warrant-constituting fact. ${ }^{27}$

In light of these differences, it would be wrong to conclude that Minimal Internalism renders non-inferential warrant inferential. It does impose a necessary condition on noninferential warrant to the effect that some proposition has to have warrant for the subject, but while such a necessary condition is also in force in cases of inferential warrant, non-

\footnotetext{
${ }^{26} \mathrm{Cf}$., in this connection, Alston's discussion of the distinction between two versions of Perspectival Internalism (Alston, "Internalism and Externalism in Epistemology," pp. 182-84).

${ }^{27}$ This contrast might disappear on some views as a result of other commitments. Thus, e.g., BonJour thinks that a warrant-constituting fact $F$ has to probabilify the proposition $p$ on which it confers warrant and that the subject has to have warrant for the probabilification claim (see BonJour, The Structure of Empirical Knowledge, pp. 30 31 ). On some views, this would make (the singleton of) the proposition that $F$ obtains qualify as the image of $p$ under the inferential-warrant function.
} 
inferential warrant, on the minimal internalist construal, remains importantly different from inferential warrant. This blocks the route from (B) to (A), and hence the reductio with which the internalist argument seeks to establish that non-inferential warrant is impossible. The argument fails to show that the internalist cannot endorse the foundationalist account of how warrant is possible, and hence internalist foundationalism survives this attack. ${ }^{28}$

Nevertheless, this attempt to vindicate the availability to the internalist of the foundationalist response to the regress argument may seem entirely futile. Even if the inferential-warrant function is not the total, non-circular, finitary sprouting function that the sceptical argument calls for, it might seem that something very close to it will do the job. Thus, let the warrant function be the sprouting function on a warrant set $A$ that $\operatorname{differs}$ from the inferential-warrant function in the following way: for every non-inferentially warranted proposition $p$ in $A$, if the subject has warrant for the proposition that the corresponding warrant-constituting fact $F$ obtains, then the warrant function pairs $p$ with the singleton of the proposition that $F$ obtains. Clearly, it follows from Minimal Internalism that the warrant function is total. Hence we seem to have found, after all, the function that the sceptic needsa total, non-circular, finitary function on each warrant set.

But this is too quick. In addition to being total, the function that the sceptic needs has to be non-circular and finitary. We are assuming that the inferential-warrant function satisfies these requirements, but these assumptions don't secure the same behaviour for the warrant function, as the images that the latter assigns to non-inferentially warranted propositions might generate violations of non-circularity or finitariness. Then we would have a non-circular, finitary sprouting function that isn't total (i.e. inferential warrant) and a total sprouting function that

\footnotetext{
${ }^{28}$ Of course, we could use the label inferential warrant to denote any form of warrant for a proposition that has warrant for other propositions as a necessary condition. Then $(C)$ would obviously hold, and the totality of the inferential warrant function could be successfully established by the internalist argument. But now the sceptic would face problems elsewhere, as on the broader conception of inferential warrant finitariness and noncircularity become much less compelling.
} 
isn't non-circular and finitary (i.e. warrant), but no single sprouting function satisfying the three requirements, and the regress sceptic could still be kept at bay. I am going to argue that this strategy is open to the internalist foundationalist, since she can claim with some plausibility that the warrant function doesn't satisfy the non-circularity constraint.

\section{Transparency}

Suppose that subject $S$ has non-inferential warrant for the proposition that fact $F$ obtains. Then, by Non-Primitivism, there will have to be a non-epistemic fact $G$ constituting the fact that $S$ has warrant for the proposition that $F$ obtains. And then, by Minimal Internalism, $S$ will have to have warrant for the proposition that $G$ obtains. The strategy that I want to describe arises from a crucial point that our choice of variables might make us overlook: So long as $F$ is non-epistemic, Non-Primitivism doesn't rule out the possibility that $F$ and $G$ are the same fact - that $S$ 's non-inferential warrant for the proposition that $F$ obtains is constituted by $F$ itself. Let me introduce the notion of transparency to represent this phenomenon:

A non-epistemic fact $F$ is transparent to a subject $S$ (at time $t$ ) just in case $F$ constitutes the fact that the proposition that $F$ obtains has warrant for $S$ (at $t$ ).

If there were transparent facts, they could play a crucial role in a strategy for resisting the regress argument along foundationalist lines without abandoning Minimal Internalism.

To see this, consider first how a proposition representing a transparent fact would behave with respect to the warrant function. If $p$ has non-inferential warrant for $S$, and $p$ represents a transparent fact, then the image of $p$ under the warrant function will be the singleton of $p$. The resulting one-node loop will constitute a direct violation of the non-circularity constraint (I shall refer to loops of this kind as transparency loops). Therefore, if there were transparent facts, the warrant function would not satisfy the non-circularity constraint, and hence it could 
not be used to run the regress argument. Notice, however, that the resulting situation is perfectly compatible with the foundationalist picture. For rejecting the non-circularity constraint on the warrant function doesn't force us to reject the corresponding constraint on the inferential-warrant function. Hence we can accept the existence of transparent facts while still subscribing to the non-circularity and finitariness constraints on the inferential-warrant function, as foundationalism dictates. ${ }^{29}$

Furthermore, accepting the existence of transparent facts would not put any pressure whatsoever on Minimal Internalism. Notice that, if a subject $S$ has non-inferential warrant for a proposition $p$, and $p$ represents a transparent fact, the fact constituting $p$ 's warrant will be the very same fact that $p$ represents. And this will have the curious effect of rendering Minimal Internalism entirely vacuous with respect to $p$. The condition that it imposes on $p$ having warrant for $S$ is that $p$ has warrant for $S$. I.e. $p$ 's warrant for $S$ can never violate Minimal Internalism. Hence we can accept the existence of transparent facts while still subscribing to the minimal internalist demand that a subject can have non-inferential warrant for a proposition only if she has warrant for the proposition representing the corresponding warrant-constituting fact. In sum, transparent facts would sustain a strategy for blocking the regress argument that is perfectly compatible with internalist foundationalism.

We can get a better sense of the proposal if we consider the shape of the warrant trees that it would generate. If $p$ is an inferentially warranted proposition, its warrant tree will start with a finitary, non-circular inferential-warrant tree. Each branch of this inferential-warrant tree will end with a non-inferentially warranted proposition $q$. If $q$ represents a transparent fact, this branch of the warrant tree for $p$ will end with a transparency loop. If $q$ doesn't represent a transparent fact, then the branch will continue with the singleton of the proposition, $r$,

\footnotetext{
${ }^{29}$ Transparency doesn't force us to abandon the finitariness of the warrant function, and I am going to assume here that this requirement is still in force. I shall also assume that transparency loops are the only allowed violations of the non-circularity of the warrant function.
} 
representing the corresponding warrant-constituting fact. If $r$ is non-inferentially warranted, we have the same two possibilities as with $q$. If $r$ is inferentially warranted, then the tree will continue with an inferential-warrant tree for $r$, with the same features as the tree that we described for $p$. Each of these possibilities can obtain any number of times along the branches of the warrant tree for $p$, but the tree as a whole will be finitary, as well as 'almost' noncircular: each branch will end with a transparency loop, and these will be the only violations of non-circularity in the tree. ${ }^{30}$

\section{Translucence}

I have argued in the previous section that if there were transparent facts, the internalist foundationalist would have at her disposal a strategy for defusing the threat of the regress argument. I want to sketch two approaches to the task of implementing this strategy. Naturally, the first step towards discharging this task is to identify a range of facts for which transparency status can be plausibly claimed.

The question, whether the facts in a certain range are transparent, cannot receive a definitive answer until we have an account of the constitution relation, in terms of which transparency is defined. And this task lies outside the scope of this paper. Nevertheless, it seems plausible to expect that the facts that are transparent for a subject $S$ will be found among those which are warrant sources (relative to $S$ ) for propositions that represent them, or, at a minimum, positive conditions of such warrant sources.

I am going to represent this phenomenon using the notion of translucence, defined as follows:

\footnotetext{
${ }^{30}$ See the previous footnote. Notice that I am not arguing for the claim that transparency loops are the only legitimate violations of circularity in the warrant function. My point is that transparency loops are the only violations that we need to allow in order to deal with the internalist argument.
} 
A range of facts $R$ is strongly translucent for a subject $S$ just in case, for every fact $F$ in $R, F$ is a warrant source (relative to $S$ ) for the proposition that $F$ obtains.

A range of facts $R$ is (weakly) translucent for a subject $S$ just in case, for every fact $F$ in $R, F$ is the positive condition of a warrant source (relative to $S$ ) for the proposition that $F$ obtains.

It will be useful to have a correlate notion for families of propositions:

A family of propositions $\Pi$ is strongly translucent for a subject $S$ just in case, for every proposition $p$ in $\Pi$, the truth of $p$ is a warrant source for $p$ (relative to $S$ ).

A family of propositions $\Pi$ is (weakly) translucent for a subject $S$ just in case, for every proposition $p$ in $\Pi$, the truth of $p$ is the positive condition of a warrant source for $p$ (relative to $S)$.

My working hypothesis in what follows is that facts in a strongly translucent range can in principle be expected to be transparent. For weakly translucent ranges, the hypothesis will be restricted to cases in which the associated defeaters are not satisfied.

\section{Two Types of Internalist Foundationalism}

Implementing the anti-sceptical strategy that I have described requires finding a range of transparent facts to supply the end points of the branches of warrant trees. My goal in this section is to sketch two approaches to this task and to assess them from the point of view of the hypothesis introduced in the previous section.

The first approach that I want to consider can be regarded as a version of traditional internalist foundationalism. Its basic idea would be to claim transparency status for the facts 
in which traditional foundationalists located the foundations of empirical knowledge, i.e. phenomenal states of the subject — the facts represented by true experiential propositions. ${ }^{31}$

In order to assess the plausibility of this approach, we need to consider the claim that phenomenal facts are translucent to the subject—i.e. that they are (positive conditions of) warrant sources, for the relevant subject, for propositions representing them. Needless to say, different accounts of the nature of warrant are likely to dictate opposing verdicts on this claim. I want to avoid as far as possible committing myself to a substantive account of warrant, so I am going to restrict myself to assessing the claim with respect to our 'low-level' intuitions concerning who knows what. As a result, even if my characterisation of these intuitions is accepted, I will be able to claim no more than a prima facie presumption in favour of my conclusions.

From this intuitive point of view, it seems to me that the claim that the claim that experiential propositions are translucent to the subject is entirely plausible. Under normal circumstances, if $S$ is in pain at $t$, intuition dictates that the proposition I am in pain now has warrant for $S$ at $t$, and hence that, if $S$ believes this proposition at $t$, this belief has the status of knowledge. ${ }^{32}$ A similar situation obtains for propositions describing the character of the subject's sensory experience. Suppose that a red, square patch occupies the approximate

\footnotetext{
${ }^{31}$ Chisholm accords this status to the instantiation by the subject of a range of properties that he calls selfpresenting (properties, in his definition, that only entail properties including the property of thinking). The claim is expressed by his principle M1: "If the property of being F is self-presenting, if S is F, and if S believes himself to be F, then it is certain for S that he is F" (Roderick M. Chisholm, Theory of Knowledge, 3rd ed. (Englewood Cliffs, N.J.: Prentice Hall, 1989), p. 19).

${ }^{32}$ One could argue that there are exceptional circumstances under which intuition dictates a different verdict. Suppose that Damian, who is terrified of needles, sees that the nurse is about to give him a jab. As the needle is about to touch his arm, he closes his eyes and immediately forms the belief that he is in pain, even though the nurse has aborted the procedure in the last second. We might want to describe this case by saying that even though Damian believes that he is in pain, he is actually not in pain. Now suppose that the situation is like this, but now, as Damian closes his eyes, a wasp stings his arm, but the belief that he is in pain stills results from the anticipation of the needle, not from the wasp sting, which he is too anxious to notice. One might then want to say that, even though Damian is in pain, he doesn't have warrant for the proposition that he is in pain. Making room for this kind of case would require giving up the claim that phenomenal facts are strongly transparent. However, if failure of warrant in these cases could be explained in terms of defeaters associated with the warrant sources of which phenomenal facts are positive conditions, the claim that these facts are weakly transparent would not be under threat.
} 
middle of $S$ 's visual field at $t$. Then, under normal circumstances intuition dictates that $S$ has warrant at $t$ for the proposition that her visual field exhibits this feature, and that, if she has the corresponding belief, it has the status of knowledge.

Thus this strategy would ascribe to experiential propositions the same foundational status as traditional foundationalism. Nevertheless it is important to see that the specific claim that these propositions are translucent is substantially different from other claims that traditional foundationalists have made about them.

Notice first that from the claim that a proposition $p$ is translucent for a subject $S$ it does not follow that $S$ is infallible about $p$ - that $S$ 's believing that $p$ entails that $p$ is true. ${ }^{33}$ The definition of translucence is perfectly compatible with the possibility that a subject believes a false proposition that is translucent for her. Actually, the fact that the propositions representing a class of states of affairs $R$ are translucent for a subject $S$ has no consequences whatsoever concerning the reliability of $S$ with respect to $R$. The propositions representing $R$ might be translucent for $S$ even if most of $S$ 's beliefs about $R$ are false.

Second, the claim that $p$ is translucent for $S$ doesn't entail either that $S$ is omniscient about $p$ - that if $p$ is true, then $S$ will believe that $p .{ }^{34}$ If $p$ is a true proposition that is translucent for $S$, then under normal circumstances $p$ will have warrant for $S$, but it doesn't follow from this that $S$ believes that $p$, since we are assuming that a subject can have warrant for propositions that she doesn't believe. ${ }^{35}$

Third, some foundationalists have claimed that experiential propositions have the following property: being believed by the subject is a sufficient condition for their having

\footnotetext{
${ }^{33}$ Hence translucence claims do not fall prey to the standard objections to infallibility. See, e.g., D. M. Armstrong, A Materialist Theory of the Mind (London: Routledge \& Kegan Paul, 1968), pp. 104-07.

${ }^{34}$ This feature saves translucence claims from an objection that James Van Cleve has raised against a similar move. Cf. Van Cleve, "Epistemic Supervenience and the Circle of Belief," p. 102, fn. 12.

${ }^{35}$ Notice that Chisholm's principle M1 also leaves open the possibility of a subject instantiating a self-presenting property while not believing that she instantiates it.
} 
warrant for her. Following Alston, I shall refer to this property as self-warrant. ${ }^{36}$ Self-warrant is importantly different from translucence. ${ }^{37}$ In a nutshell, whereas translucence makes warrant contingent on truth, self-warrant makes warrant contingent on belief. In consequence, translucence doesn't entail self-warrant: If $p$ is a false proposition that is translucent for $S$, then $S$ can believe that $p$ but fail to have warrant for $p$. Nor does self-warrant entail translucence: If $p$ is a self-warranted proposition that $S$ doesn't believe, then $S$ can lack warrant for $p$ even if $p$ is true.

Fourth, the claim that a fact $F$ is translucent for a subject $S$ doesn't entail that $S$ has noninferential reasons or evidence for thinking that $F$ is likely to obtain. It entails, of course, that $S$ has warrant for the proposition that $F$ obtains, but it would only follow from this that $S$ has the requisite reasons in the presence of a principle along the lines of RW - and an advocate of translucent facts might not subscribe to this principle.

We can now characterise the contrast between BonJour's claim regarding experiential propositions and the claim that these propositions are translucent. BonJour is claiming that the subject has non-inferential reasons for thinking that experiential propositions are likely to be true, whereas the claim that these propositions are translucent would not have any consequences to this effect. Furthermore, the epistemic status that BonJour ascribes to experiential propositions is not in any way contingent on their truth value, whereas translucence entails warrant only for true propositions. ${ }^{38}$

I am not going to pursue the question of the transparency of experiential propositions any further. I only want to register the conviction that the claim that they are transparent has a

\footnotetext{
${ }^{36}$ See William P. Alston, "Self-Warrant: A Neglected Form of Privileged Access," American Philosophical Quarterly 13 (1976).

${ }^{37}$ Alston already noted the contrast between self-warrant and transparency, for which he uses the label truthwarrant (he calls it truth-sufficiency in an earlier paper). Cf. Ibid.: pp. 261-62.

${ }^{38}$ In fact, BonJour is concerned with the epistemic status of beliefs, but it is natural to translate his view into a position concerning the epistemic status of propositions that makes it contingent on belief.
} 
much better chance of success than the other foundationalist claims about them from which we have distinguished it. If the transparency of experiential propositions could be established, then true experiential propositions, with their corresponding transparency loops, could provide the end-points of warrant trees that satisfy the conditions imposed by internalist foundationalism. Nevertheless, the internalist foundationalist would still face a major hurdle. The problem is that experiential propositions might turn out to be an insufficient starting point to generate warrant trees for even the least audacious propositions about the 'external' world. ${ }^{39}$ Concerning this problem, all too familiar to the internalist foundationalist tradition, the present proposal doesn't seem to enjoy an advantage over other versions of the view.

Let me now turn to the second proposal that I want to consider. Unlike the previous one, this strategy is markedly different in structure from traditional forms of internalist foundationalism. It is in fact best introduced as a variant of the form of foundationalism that a reliabilist account of warrant would generate. Let me use, following Goldman, the label processes to refer to a subject's basic (native) psychological processes of belief formation. ${ }^{40}$ Let $S$ be a subject with a standard battery of processes, including perception, memory, introspection, etc, and suppose that $S$ 's processes are reliable. Then, according to reliabilism, if $S$ forms the belief that $p$ with one of her processes, $p$ will have non-inferential warrant for $S^{41}$ This approach enables the reliabilist to count on a much richer body of non-inferentially warranted propositions than the traditional foundationalist could dream of. Using them as the end points of inferential-warrant trees would seem to give her a sporting chance of generating fairly substantial warrant sets.

\footnotetext{
${ }^{39}$ BonJour sees this as the main obstacle to his version of internalist foundationalism. Cf. BonJour, "The Dialectic of Foundationalism and Coherentism," p. 139.

${ }^{40}$ See Alvin I. Goldman, Epistemology and Cognition (Cambridge, Mass.: Harvard University Press, 1986), pp. 93-95.

${ }^{41}$ For the sake of simplicity, I am ignoring Goldman's non-undermining provision. Cf. Ibid., pp. 62-63.
} 
But this gain appears to come at a price, since adopting this strategy seems to force us to abandon internalist constraints on warrant. Let's consider how this result is reached in the case of Minimal Internalism. Notice first that the reliabilist has no problem satisfying NonPrimitivism. On the reliabilist picture, if $S$ has formed the belief that $p$ with a reliable process, then this fact constitutes the fact that $p$ has warrant for $S$. But then, in order to satisfy Minimal Internalism, the proposition that $S$ formed the belief that $p$ with a reliable process would have to have warrant for her. Hence, if it is possible for $S$ to have formed a belief with a reliable process while not having warrant for the proposition that her belief has been formed in this way, the reliabilist will have to abandon Minimal Internalism. It follows that rendering reliabilism compatible with Minimal Internalism would require arguing that this is not a possibility - that, under normal circumstances, when $S$ has formed a belief with a reliable process, she has warrant for the proposition that the belief has been formed in this way. This is undoubtedly a serious challenge, but if it could be met, we would have removed the main obstacle faced by a novel and appealing position — a version of internalist foundationalism based on reliabilist principles. I want to end the paper sketching a strategy for meeting this challenge.

In order to discharge this task, we would need to show that, in circumstances in which reliabilism treats reliable formation as sufficient for warrant, if $S$ forms a belief with a reliable process, she has warrant for the proposition that the belief was formed in this way. So assume that $S$ has formed the belief that $p$ with a process, $A$, which is reliable. I think we can safely assume that if $S$ had warrant for the proposition (a) that her belief that $p$ was formed with $A$ and the proposition (b) that $A$ is a reliable process, then $S$ can be expected to have inferential warrant for the proposition that her belief that $p$ was formed with a reliable process. Hence, in order to achieve our goal, it would suffice to show that $S$ has warrant for (a) and (b). 
Notice that, in order to reach this conclusion, it would suffice to establish that the fact that $S$ formed her belief that $p$ with $A$ and the fact that $A$ is reliable are transparent for $S$, as this would entail that $S$ has warrant for the propositions which represent these facts, namely (a) and (b). Hence, if we could show that facts to the effect that a subject has formed a belief with a certain process, and that this process is reliable, are transparent to the subject, we would have removed the source of the perceived incompatibility between reliabilism and Minimal Internalism.

According to our working hypothesis, we can assess the plausibility of these claims by considering whether these families of facts are translucent—whether they are (positive conditions of) warrant sources (for the relevant subject) for propositions representing them. As in the case of phenomenal facts, I am going to restrict myself to considering how these claims fare with respect to our epistemological intuitions. The issue is whether intuition dictates that, if a subject has formed a belief with a certain process and this process is reliable, she has warrant for the propositions representing these facts. I want to suggest that, so long as process are individuated along folk-psychological lines, as, e.g., looking, listening, remembering, etc, intuition is firmly in favour of ascribing warrant to these propositions, and hence of treating them as translucent.

Let's look first at propositions concerning the identity of processes. If $S$ has formed the belief that there is a milk carton in the fridge by seeing the carton there, then it seems to me that under normal circumstances we have a strong intuition to the effect that $S$ has warrant for the proposition that her belief was formed in this way. Recall that this doesn't entail that she believes this proposition, that her believing a proposition of this kind entails that it is true, or that she has reasons for thinking that the proposition is probably true. All it means is that, in 
normal circumstances, true belief in a proposition of this kind seems sufficient for knowledge. $^{42}$

And the same can be said, I submit, about true propositions to the effect that the processes with which our beliefs have been formed are reliable. Intuition dictates that, under normal circumstances, if one of S's folk-psychological processes is reliable, then the proposition that this process is reliable has warrant for $S$. S, again, might not believe this proposition, she might falsely believe that one of her processes is reliable and she might have no reason for thinking that the process is reliable. But if the process is reliable, and she believes that it is, then under normal circumstances intuition accords to this belief the status of knowledge. ${ }^{43} 44$

Even if this characterisation of our epistemological intuitions is accepted, we are still a long way from showing that facts about the reliability of a subject's processes and about which process a belief has been formed with are transparent to her. In any case, my main point is that if these conclusions could be established, we would have at our disposal a thoroughly new version of internalist foundationalism — one that exploits the anti-sceptical power of reliabilist principles without abandoning Minimal Internalism.

\section{APPENDIX}

Definition: A sprouting function on a set $A$ is a function from $A$ to $\wp(A)$.

Definition: If $f$ is a sprouting function on a set $A$, and $a \in A$, then the $f$-tree of $a$ is the smallest $A^{*} \subseteq A$ satisfying the following conditions:

(a) $\quad f(a) \subseteq A^{*}$.

\footnotetext{
${ }^{42}$ Here we may be forced to make a similar move to the one described in $\mathrm{fn} .32$ concerning the translucence phenomenal facts.

${ }^{43}$ See the previous footnote.

${ }^{44}$ See my "Externalism, Skepticism and the Problem of Easy Knowledge", §7, where I argue, in effect, that the reliabilist should have no problem accepting the translucence of reliability facts.
} 
(b) For every $x \in A^{*}, f(x) \subseteq A^{*}$.

Recall that a choice function for a set $A$ is a function pairing each nonempty subset of $A$ with one of its elements.

Definition: If $f$ is a sprouting function on $A$, and $a \in A$, then, for every choice function $g$ for $A$, the $f$-branch of $a$ generated by $g$ is the smallest $A^{*} \subseteq A$ satisfying the following conditions:

(a) If $f(a) \neq \varnothing$, then $g(f(a)) \in A^{*}$.

(b) For every $x \in A^{*}$, if $f(x) \neq \varnothing$, then $g(f(x)) \in A^{*}$.

Definition: A sprouting function $f$ on a set $A$ is total if for every $x \in A, f(x) \neq \varnothing$.

Definition: A sprouting function $f$ on a set $A$ is non-circular if for every $a \in A, a$ is not an element if the $f$-tree of $a$.

Definition: A sprouting function $f$ on a set $A$ is finitary if every $f$-branch in $A$ is finite.

Agrippa's Theorem: If $A$ is a nonempty set, there are no total, non-circular, finitary sprouting functions on $A$.

Proof: Let $A$ be a nonempty set, and let $f$ be a total, non-circular sprouting function on $A$. We establish Agrippa's Theorem by showing that there is at least one infinite $f$-branch in $A$. Let $a$ $\in A$, and let $g$ be a choice function for $A$. Consider the following enumeration of elements of A:

$$
\begin{aligned}
& t_{1}=g(f(a)) \\
& \text { For every } n, t_{n+1}=g\left(f\left(t_{n}\right)\right)
\end{aligned}
$$

Notice that, since $f$ is total, $g(f(b))$ exists for every $b \in A$. 
Clearly every $t_{i}$ is in the $f$-branch of $a$ generated by $g$. Hence, to show that this branch is infinite, it will suffice to show that for all $m, n$ such that $m \neq n, t_{m} \neq t_{n}$. Let $m<n$. Then $t_{n}$ is in the $f$-tree of $t_{m}$, and since $f$ is non-circular, it follows that $t_{m} \neq t_{n}$, as desired. 